\title{
Biomass carbon ratio of biobased polymer composites filled with cellulose fibers measured by accelerator mass spectrometry
}

\author{
M. Funabashi ${ }^{1}$, A. Listyarini ${ }^{2}$ \& M. Kunioka ${ }^{1}$ \\ ${ }^{I}$ Research Institute for Innovation in Sustainable Chemistry, \\ National Institute of Advanced Industrial Science and Technology (AIST), \\ Japan \\ ${ }^{2}$ Center for Chemical and Packaging, \\ Agency for Industrial Research and Development, Ministry of Industry, \\ Indonesia
}

\begin{abstract}
Composite samples were made of poly(butylene succinate) (PBS) and cellulose fillers. Cellulose powders, cotton fibers, and fibers derived from trunks, frond petioles, and an oil palm empty fruit bunch were used as fillers of composite samples. A sheet of the composite was made by hot-pressing the mixture of PBS powders and fillers. Oil palm tree fibers were observed by an optical microscope. Thermal degradations of these fibers were measured by thermogravimetry. The biomass carbon ratio of the starch and wood were described. The biomass carbon ratio of the PBS composites with cellulose fibers was investigated. The mechanical properties of the PBS composites were measured by tensile test using dumbbell specimens. The possibility of an evaluation method of biomass carbon ratio of composite materials was shown.
\end{abstract}

Keywords: polymer composite, poly(butylene succinate) (PBS), oil palm tree, accelerator mass spectrometry (AMS), biomass carbon ratio.

\section{Introduction}

Recently, biodegradable plastics and biobased polymers have been widely used in various industrial fields to save resources and reduce evolved carbon dioxide gas. Poly(lactic acid), poly( $\varepsilon$-caprolactone) and poly(butylene succinate) are 
typical examples of biodegradable plastics. Some of the physical properties, such as mechanical properties and thermal properties, of these polymers are rather lower than those of ordinary polymers derived from petroleum. The mechanical properties and thermal properties of these polymers can be improved by the reinforcement of fillers. Namely, polymer composites consist of biodegradable plastics and fillers. For actual use, the cost of production is one of the most important things. From this point of view, the use of natural fillers for these composites is useful. The use of natural fillers for the composite can also bring a saving in energy during production and resources. In addition, these composites can be treated as wastes after use with less energy and less carbon dioxide.

Nowadays, large amounts of waste from agriculture are another worldwide problem. For example, palm oil in Malaysia is one of the biggest agroindustries and a large amount of waste is abundantly produced during the production of palm oil. Oil palm trunks, oil palm frond petioles, oil palm empty fruit bunches and other parts are obtained as waste. Most of these are landfilled as fertilizers for oil palm trees. It is known that good natural fibers can be derived from these parts.

For biodegradable polymers, it is necessary to estimate biodegradability. There are several standards on the biodegradation of plastics under the International Organization for Standardization (ISO). We have reported the results of biodegradation testing according to ISO [1-3]. For polymers derived from biomass and polymer composites using biomass, it is necessary to estimate the origin of the materials. The biomass carbon ratio is one of the values that indicate the ratio of biomass carbon atoms to total carbon atoms. The biomass carbon ratio can be estimated to measure the ratio of ${ }^{14} \mathrm{C}$ by accelerator mass spectrometry (AMS) according to ASTM D6866-06. We have already reported some results of the biomass carbon ratio of various materials [4-6].

In this study, the composites consisting of biodegradable plastics and natural fibers were prepared. Composite samples of poly(butylene succinate) (PBS) with cellulose powders and fibers from the oil palm tree were prepared by mixing PBS powders and cellulose fillers. The mechanical properties and biomass carbon ratio of the samples were investigated.

\section{Experimental}

\subsection{Materials}

Poly(butylene succinate) (PBS, 1,4-butylene succinate, Aldrich) was used as received after drying. Cellulose powders with an average diameter of $25 \mathrm{~mm}$ of AVICEL (PH-M25, Asahi Chemical Industry Co., Ltd., Japan) were used after drying. Three kinds of natural fibers obtained from different parts of palm oil trees were used after drying. These fibers from the trunk, frond and empty fruit bunch of the palm oil tree were kindly provided to us by the Malaysia Palm Oil Board (MPOB). Absorbent cotton fibers (CFC, Iwatsuki Co., Japan) are also used as fillers of composites. 


\subsection{Sample preparation}

The composite samples were prepared by hand mixing. PBS pellets with dry ice were crushed into powders by a mechanical mixer with titan blades. After drying, PBS powders with smaller than $250 \mu \mathrm{m}$ were separated by a sieve. Regulated PBS powders and fillers were mixed in a mortar by hand. A mixture was put into a stainless mold of $0.5 \times 100 \times 100 \mathrm{~mm}$. A mold was put on a hot press and was heated at $120{ }^{\circ} \mathrm{C}$. After the temperature of the plate of the hot press reaches $120^{\circ} \mathrm{C}$, a mold was pressed at $20 \mathrm{MPa}$ for $5 \mathrm{~min}$. The mold was taken out from the hot press and cooled on an iron block. After cooling, a sheet specimen was removed from the mold.

\subsection{Optical microscope observation}

The fibers were observed using an Olympus BH-2. Microphotographs were taken using a digital camera.

\subsection{Thermogravimetry (TG)}

TG was carried out in air using a Seiko TG 220 at a heating rate of $10{ }^{\circ} \mathrm{C} \mathrm{min}{ }^{-1}$ in the temperature range from 30 to $550{ }^{\circ} \mathrm{C}$. The peak temperatures $\left(\mathrm{DTd} \mathrm{d}_{1}\right.$ and $\mathrm{DTd} \mathrm{d}_{2}$ ) were observed from derivative thermogravimetry (DTG) curves. The mass residue of samples at $450{ }^{\circ} \mathrm{C}$ (MR450) was determined from the TG curves.

\subsection{Tensile test}

The mechanical properties of tensile tests were determined using a Shimadzu Autograph AG-1000B according to ISO 527-3 with dumbbell shaped specimens with a thickness $0.5 \mathrm{~mm}$. The test speed was $10 \mathrm{~mm} / \mathrm{min}$. The strength and elastic modulus were investigated as the mechanical properties of the samples. The strength of samples was determined as a maximum stress from the stress-strain curve. The elastic modulus was determined as a gradient of the initial linear part of the stress-strain curve. The strain at break was also obtained from a stress-strain curve. The averages of the above values were obtained using three specimens for each measurement.

\subsection{Measurement of the biomass carbon ratio}

The measurement of the ratio of the three carbon isotopes $\left({ }^{14} \mathrm{C},{ }^{13} \mathrm{C}\right.$, and $\left.{ }^{12} \mathrm{C}\right)$ using AMS was performed at the Institute of Accelerator Analysis Ltd., Japan (IAA) based on ASTM D-6866-06. These measurement methods have been developed for dating historical and geological samples to determine when the samples were produced and used. The AMS measurement procedure has already been reported in our previous works [4-6]. The ratio of ${ }^{14} \mathrm{C}$ to ${ }^{12} \mathrm{C}$ concentrations $\left({ }^{14} \mathrm{As}\right)$ for samples was calculated from the measured amounts of ${ }^{14} \mathrm{C}$ and ${ }^{12} \mathrm{C}$. The percentage of modern carbon (pMC) for an oil-based carbon is $0 \%$, since all of the ${ }^{14} \mathrm{C}$ in oil has already decayed during storage on the earth. The pMC for 
biomass made from the fixation of $\mathrm{CO}_{2}$ in the modern atmosphere through photosynthesis was $108-110 \%$ in 2002 . The measurement of products ${ }^{14} \mathrm{As}$ $\left({ }^{14} \mathrm{C} /{ }^{12} \mathrm{C}\right)$ is determined as relative to the modern carbon-based oxalic acid radiocarbon [7].

\section{Results and discussion}

\subsection{Optical microscopy of fibers}

The microphotographs of fibers derived from different parts of the palm tree are shown in fig. 1. Fibers from the trunk and frond have almost the same diameter and length. The diameter of fibers from the empty fruit bunch is thinner than those of the other two kinds of fibers. Small particles are observed with empty fruit bunch fibers.

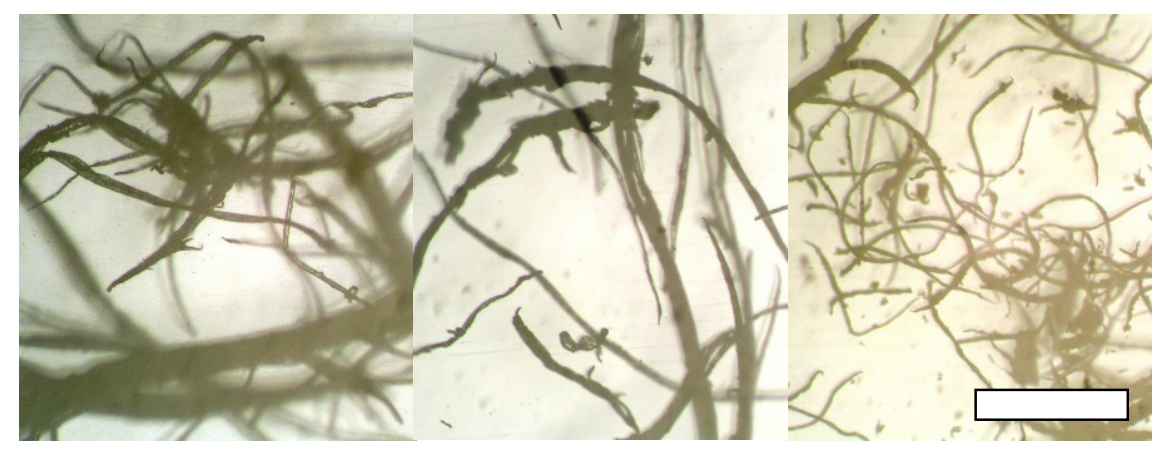

Figure 1: Microphotographs of fibers of the trunk, frond petiole, and empty fruit bunch from the oil palm tree; white bar $=0.05 \mathrm{~mm}$.

\subsection{Thermogravimetry (TG) analysis of fibers}

Thermal degradations of three kinds of fibers derived from different parts of the oil palm tree were studied by TG analysis. Thermogravimetry (TG) curves and derivative TG (DTG) curves are shown in fig. 2. Thermal degradation of these fibers seems to start at around $250{ }^{\circ} \mathrm{C}$. Two peaks of DTG curves are mainly observed. Two peak temperatures of DTG curves and mass residue at $450 \mathrm{oC}$ are shown in table 1. The temperatures of these peaks for three fibers in table 2 are different from each other. It is thought that thermal degradations of fibers proceed in different steps. These results agree with the microscopy of the outsides of fibers as shown in fig. 1.

\subsection{Results of tensile tests}

The mechanical properties of poly(butylene succinate) (PBS) composite samples were investigated by tensile tests. Tensile test results of PBS composites with 
cellulose powders (AVICEL) are shown in fig. 3. Tensile strength and strain at the break are shown in fig. 3. Tensile strength decreases monotonously increasing with the content of cellulose powders. Strain at break shows the maximum values at a filler content of $20 \%$. It is thought that cellulose powders make a higher plasticity of the PBS matrix. The improvement of strength by fibers cannot be observed.

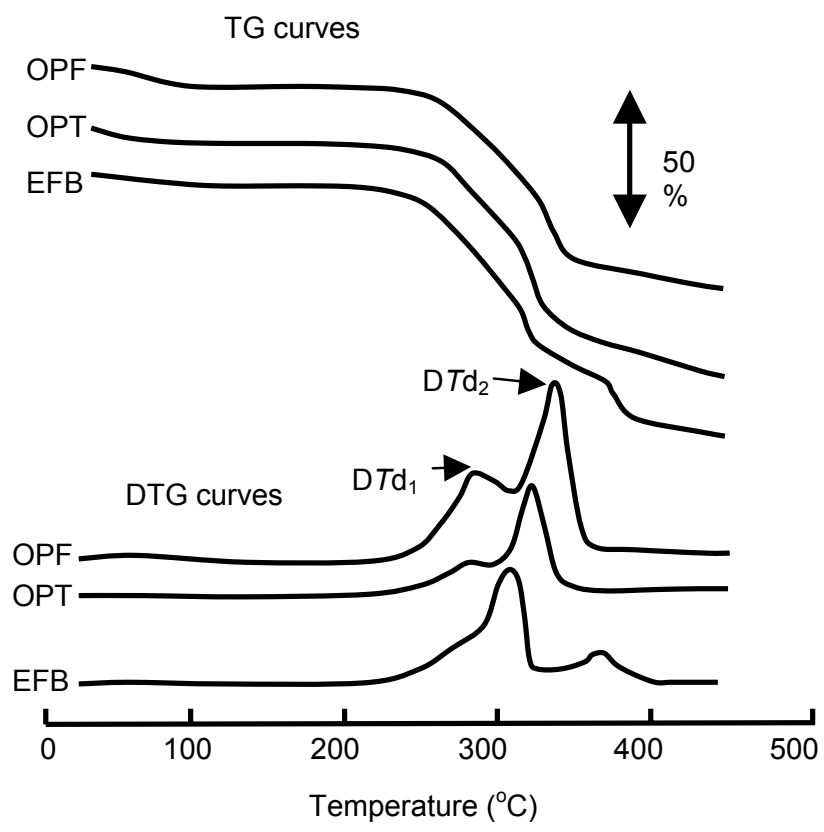

Figure 2: Thermogravimetry (TG) curves and derivative TG curves for fibers of the frond petiole (OPF), trunk (OPT) and empty fruit bunch $(\mathrm{EFB})$ from the oil palm tree.

Table 1: $\quad$ Peak temperatures of derivative thermogravimetry curves $\left(\mathrm{D} T \mathrm{~d}_{1}\right.$ and $\left.\mathrm{DTd} \mathrm{d}_{2}\right)$ and mass residue at $450{ }^{\circ} \mathrm{C}(M R 450)$ for fibers of the frond petiole (OPF), trunk (OPT) and empty fruit bunch (EFB) from the oil palm tree.

\begin{tabular}{cccc}
\hline & \multicolumn{2}{c}{ Peak temperature $\left({ }^{\circ} \mathrm{C}\right)$} & \multirow{2}{*}{ MR450 $(\%)$} \\
\cline { 2 - 3 } fibers & $\mathrm{DTd}_{1}$ & $\mathrm{DTd}_{2}$ & \\
\hline OPF & 330 & 349 & 19.8 \\
OPT & 293 & 335 & 10 \\
EFB & 312 & 369 & 6.5 \\
\hline
\end{tabular}


Table 2: $\quad$ Percentage modern carbon and biomass carbon ratio of various plant powders.

\begin{tabular}{|c|c|c|c|c|}
\hline Fun & Material & $\mathrm{pMC}(\%)$ & $\begin{array}{c}\text { Biomass carbon } \\
\text { ratio }(\%)\end{array}$ & $\begin{array}{l}\text { Age } \\
\text { (year) }\end{array}$ \\
\hline 1 & 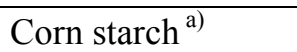 & 106 & 98 & 2005 \\
\hline 2 & Potato starch ${ }^{\text {b) }}$ & 108 & 100 & 2005 \\
\hline 3 & Rice $\operatorname{starch}^{\text {c) }}$ & 106 & 98 & 2005 \\
\hline 4 & Sugar beet starch ${ }^{\text {d) }}$ & 108 & 100 & 2005 \\
\hline 5 & Cedar $^{\mathrm{e})}$ (core) & 153 & 143 & 1935 \\
\hline 6 & Cedar $^{\mathrm{e})}$ (near core) & 150 & 140 & 1940 \\
\hline 7 & Cedar $^{\mathrm{e})}$ (near side) & 112 & 104 & 2000 \\
\hline 8 & Cedar $^{\mathrm{e})}($ side $)$ & 107 & 99 & 2005 \\
\hline 9 & Cellulose powder ${ }^{\text {f) }}$ & 121 & 113 & -- \\
\hline 10 & Cotton fiber ${ }^{\mathrm{g})}$ & 109 & 101 & $(2000)$ \\
\hline
\end{tabular}

a) Starch from corn harvested on USA.

b) Starch from potato harvested on Japan.

c) Starch from rice harvested on Japan.

d) Starch from sugar beet harvested on Japan.

e) Japanese cedar (Sugi, estimated age 80 years) harvested in Japan.

f) Cellulose powder (AVICEL, Asahi Chemical Inc., Japan).

g) Absorbent cotton (CFC, Iwatsuki Co., Japan).

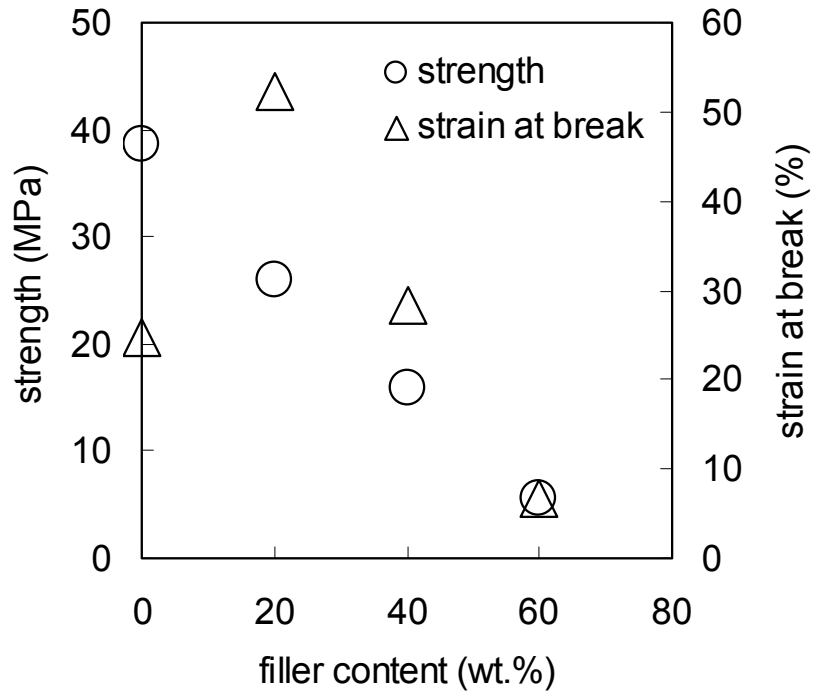

Figure 3: Tensile strength and strain at break of poly(butylene succinate) (PBS) with cellulose powders. 
Tensile test results of PBS composites with fibers of the oil palm tree are shown in figs. 4 and 5. Fig. 4 shows the strength of composite samples with three kinds of fibers derived from the frond petiole (OPF), trunk (OPT) and empty fruit bunch (EFB) of the oil palm tree. Fig. 4 shows strain at break by tensile tests for composites with OPF, OPT and EFB fibers. The strength of composites gradually decreases with increasing fiber content as shown in fig. 4. Strain at break of composites rapidly decreases with increasing fiber content as shown in fig. 5. The mechanical properties of PBS cannot be improved by oil palm tree fibers. $20 \mathrm{wt} . \%$ of fibers seems to be insufficient for mechanical improvement. When fibers greater than 20 wt.\% are combined with the PBS matrix, the mechanical properties may be improved.

\subsection{Biomass carbon ratio measurements}

Biomass carbon ratios were measured by AMS. The percentage modern carbon (pMC) and biomass carbon ratio of several kinds of plant materials are shown in table 2. Runs 1 to 4 are starch derived from different vegetables. Values of pMC for these samples are almost $107 \%$ and values of biomass carbon ratio derived from pMC are almost $100 \%$. Runs 5 to 8 are different parts of the Japanese cedar. The estimated age of this tree is 80 years old. It is known that an amount of ${ }^{14} \mathrm{C}$ increases by nuclear tests and nuclear bombs. During the period from 1940 to 1960 , several nuclear tests were performed in air. The core part of this

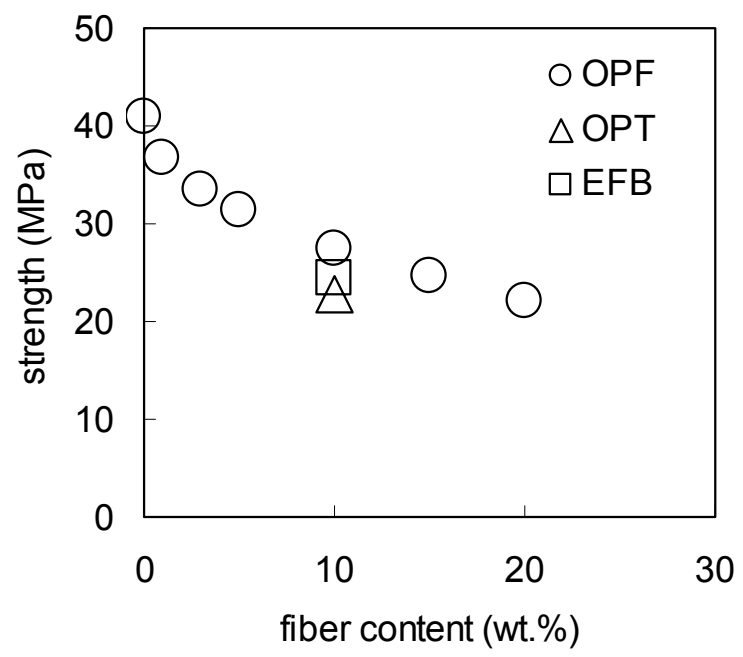

Figure 4: $\quad$ Tensile strength of poly(butylene succinate) (PBS) with fibers of the trunk (OPT), frond petiole (OPF), and empty fruit bunch (EFB) from the oil palm tree. 


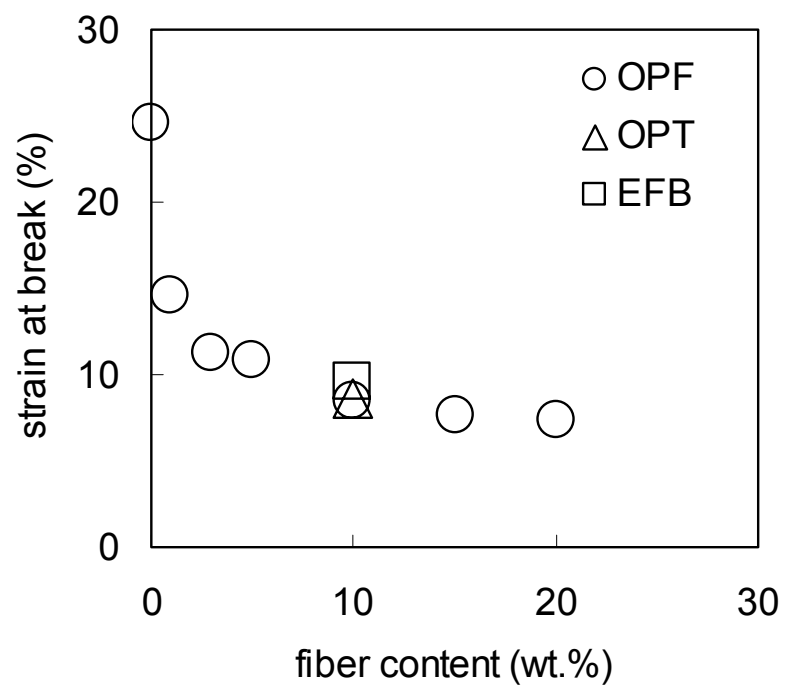

Figure 5: $\quad$ Strain at break of poly(butylene succinate) (PBS) with fibers of the trunk (OPT), frond petiole (OPF), and empty fruit bunch (EFB) from the oil palm tree.

tree may be produced around 80 year ago by the tree itself. This part may include a higher content of ${ }^{14} \mathrm{C}$. Therefore, the biomass carbon ratio of this part is much higher than $100 \%$. Biomass carbon ratios of yearly plants, such as grasses and vegetables, are almost $100 \%$. However, biomass carbon ratios of perennial plants such as woods are strongly affected by age. It is necessary, for these materials, to recalculate biomass carbon ratios with some correction factor, which can be automatically calculated using pMC. These results indicate that the biomass carbon ratio of plant materials can be estimated by pMC measured by AMS.

Biomass carbon ratios of poly(butylene succinate) (PBS) composites with cellulose fillers are shown in table 3. PBS used in this study is made from petroleum. Therefore, biomass carbon ratio of PBS is almost $0 \%$ as shown in table 3. The biomass carbon ratio of cellulose powders is $113 \%$ and that of cotton fibers is almost $100 \%$, as shown in table 2. It is thought that these cellulose powders may be derived in the 1970s. The filler content of PBS composites with cellulose filler is $5 \%$ and the biomass carbon ratios of these samples are $4.5 \%$ and $5.0 \%$, respectively. These results show that the biomass carbon ratio of composites can be estimated by AMS measurement.

\section{Conclusions}

Fibers derived from the frond petiole, the trunk and the empty fruit bunch of the oil palm tree harvested in Malaysia were used as fillers of composites. The outsides of three kinds of fibers are different from each other by observation of 
Table 3: $\quad$ Percentage of the modern carbon and biomass carbon ratio of composites consisting of poly(butylene succinate) (PCL) and cellulose powders (CP).

\begin{tabular}{ccccc}
\hline Run & \multicolumn{2}{c}{ Composition (\%) } & pMC (\%) & $\begin{array}{c}\text { Biomass carbon } \\
\text { ratio (\%) }\end{array}$ \\
\cline { 2 - 3 } & PBS $^{\text {a) }}$ & filler & & 0.5 \\
2 & 100 & 0 & 0.6 & 4.5 \\
3 & 95 & $5^{\text {b) }}$ & 4.9 & 5.0 \\
Cellulose & 95 & $5^{\text {c) }}$ & 5.3 & 113 \\
Cotton & 0 & $100^{\text {b) }}$ & 121 & 101 \\
\hline
\end{tabular}

a) Poly(1,4-butylene succinate) (Aldrich).

b) Cellulose powder (AVICEL, Asahi Chemical Inc., Japan).

c) Absorbent cotton (CFC, Iwatsuki Co., Japan).

microscopy. Three kinds of fibers were degraded in different processes during thermogravimetry. Composites consisting of poly(butylene succinate) and cellulose fillers, such as cellulose powders and fibers of the oil palm tree were prepared. The mechanical properties of these composites were investigated by the tensile tests. The strength and strain at break of composites decreases with increased filler content. The biomass carbon ratios by AMS analysis for several kinds of starch are almost $100 \%$, although biomass carbon ratios of parts of wood vary 100 to $140 \%$. Biomass carbon ratios of PBS composites with cellulose powders or cotton fibers can be measured. The biomass carbon ratio of polymer composites can be estimated by AMS analysis based on ASTM D-6866-06.

\section{References}

[1] M. Kunioka, F. Ninomiya, M. Funabashi, Biodegradation of poly(lactic acid) powders proposed as the reference test materials for the international standard of biodegradation evaluation method, Polym. Degrad. Stab., 91, pp. 1919-1928, 2006.

[2] M. Funabashi, F. Ninomiya, M. Kunioka, Biodegradation of polycaprolactone powders proposed as the reference test materials for the international standard of biodegradation evaluation method, J. Polym. Environ., 15(1), pp. 7-17, 2007.

[3] M. Funabashi, F. Ninomiya, M. Kunioka, Method of producing biodegradable reference material and its biodegradability based on international standard evaluation method (ISO/DIS 14855-2), J. Polym. Environ., 15(4), (in printing), (2007).

[4] M. Kunioka, Y. Inuzuka, F. Ninomiya, M. Funabashi, Biomass contents of biodegradable poly( $\varepsilon$-caprolactone) composites polymerized and directly 
molded using aluminum triflate from caprolactone with cellulose and inorganic filler, Macromol. Biosci., 6, pp. 517-523, 2006.

[5] M. Kunioka, F. Ninomiya, M. Funabashi, Novel evaluation method of biodegradabilities for oil-based polycaprolactone by naturally occurring radiocarbon-14 on ISO 14855-2 in controlled compost, Polym. Degrad. Stab., 92, pp. 1279-1288, 2007.

[6] M. Kunioka, F. Ninomiya, M. Funabashi, Biobased contents of organic fillers and polycaprolactone composites with cellulose filler measured by accelerator mass spectrometry based on ASTM D6866, J. Polym. Environ., 15(4), (in printing), 2007.

[7] Standard Reference Material (SRM) 4900c, National Institute of Standards and Technology (NIST), USA 